\title{
Direct inhibition of PI3K in combination with dual HER2 inhibitors is required for optimal antitumor activity in HER2+ breast cancer cells
}

Brent N Rexer ${ }^{1,2,3,4^{*}}$, Siprachanh Chanthaphaychith ${ }^{1}$, Kimberly Brown Dahlman ${ }^{2,4}$ and Carlos L Arteaga $a^{1,2,3,4}$

\begin{abstract}
Introduction: Despite multiple advances in the treatment of HER2+ breast cancers, resistance develops even to combinations of HER2 targeting agents. Inhibition of PI3K pathway signaling is critical for the efficacy of HER2 inhibitors. Activating mutations in PIK3CA can overlap with HER2 amplification and have been shown to confer resistance to HER2 inhibitors in preclinical studies.
\end{abstract}

Methods: Lapatinib-resistant cells were profiled for mutations in the PI3K pathway with the SNaPshot assay. Hotspot PIK3CA mutations were retrovirally transduced into HER2-amplified cells. The impact of PIK3CA mutations on the effect of HER2 and PI3K inhibitors was assayed by immunoblot, proliferation and apoptosis assays. Uncoupling of PI3K signaling from HER2 was investigated by ELISA for phosphoproteins in the HER2-PI3K signaling cascade. The combination of HER2 inhibitors with PI3K inhibition was studied in HER2-amplified xenograft models with wild-type or mutant PIK3CA.

Results: Here we describe the acquisition of a hotspot PIK3CA mutation in cells selected for resistance to the HER2 tyrosine kinase inhibitor lapatinib. We also show that the gain of function conferred by these PIK3CA mutations partially uncouples PI3K signaling from the HER2 receptor upstream. Drug resistance conferred by this uncoupling was overcome by blockade of PI3K with the pan-p110 inhibitor BKM120. In mice bearing HER2-amplified wild-type PIK3CA xenografts, dual HER2 targeting with trastuzumab and lapatinib resulted in tumor regression. The addition of a PI3K inhibitor further improved tumor regression and decreased tumor relapse after discontinuation of treatment. In a PIK3CA-mutant HER2+ xenograft, PI3K inhibition with BKM120 in combination with lapatinib and trastuzumab was required to achieve tumor regression.

Conclusion: These results suggest that the combination of PI3K inhibition with dual HER2 blockade is necessary to circumvent the resistance to HER2 inhibitors conferred by PIK3CA mutation and also provides benefit to HER2+ tumors with wild-type PIK3CA tumors.

\section{Introduction}

Amplification of the HER2 oncogene occurs in approximately $25 \%$ of human breast cancers and predicts response to therapies targeting human epidermal growth factor receptor 2 (HER2), including trastuzumab, a monoclonal antibody directed against HER2, and lapatinib, a tyrosine kinase inhibitor (TKI) of HER2 and

\footnotetext{
* Correspondence: brent.rexer@vanderbilt.edu

'Division of Hematology-Oncology, Department of Medicine, School of Medicine, Vanderbilt University, 2220 Pierce Avenue, 777 PRB, Nashville, TN 37232-6307, USA

2Department of Cancer Biology, Vanderbilt University, 2220 Pierce Avenue, 777 PRB, Nashville, TN 37232-6307, USA

Full list of author information is available at the end of the article
}

epidermal growth factor receptor (EGFR) [1,2]. HER2 is a member of the ErbB family of receptor tyrosine kinases (RTKs), which form both homo- and heterodimers, resulting in the activation of downstream signaling pathways [3]. In HER2-amplified cancers, the heterodimer of HER2 with kinase-deficient HER3 is a major activator of phosphoinositide 3-kinase (PI3K)-Akt signaling, and HER3, when phosphorylated, can directly couple to the p85 subunit of PI3K [4]. HER2-amplified tumors show significant reliance on PI3K-Akt signaling $[5,6]$. Importantly, inhibition of PI3K-Akt signaling is believed to be an essential component of the antitumor effect of HER2-directed therapies [7-9]. 
Alteration of the PI3K-Akt pathway is frequent in human cancers, and among the most frequent alterations are mutations in phosphoinositide 3-kinase catalytic subunit $\alpha(P I K 3 C A)$, the gene encoding the $\mathrm{p} 110 \alpha$ catalytic subunit of PI3K. These mutations cluster in hotspot regions in the helical and kinase domains of $\mathrm{p} 110 \alpha[10,11]$ and confer a gain of function [12]. PIK3CA hotspot mutations are found in approximately $25 \%$ of breast cancers and can overlap with HER2 amplification $[10,13,14]$. The presence of these mutations in HER2-amplified cancer cells confers resistance to trastuzumab or lapatinib [7,15-17]. Moreover, aberrant activation of PI3K-Akt signaling by a PIK3CA mutation and/or phosphatase and tensin homologue (PTEN) loss is associated with resistance to trastuzumab in patients in some studies $[15,18,19]$.

Recent clinical studies have suggested that targeting HER2-PI3K signaling with combinations of agents that inhibit HER2 by different mechanisms is more effective than a single HER2 inhibitor; combining trastuzumab and lapatinib was more effective than trastuzumab alone in both the metastatic and neoadjuvant settings [20,21]; and combining two HER2 antibodies, trastuzumab and pertuzumab, prolonged survival longer than trastuzumab alone [22]. Preclinical studies have suggested that the HER2/HER3 signaling complex has sufficient buffering capacity to withstand incomplete inhibition of HER2 catalytic activity, even in combination with a PI3K inhibitor, though this capacity can be overcome by fully inactivating HER2 catalytic activity with elevated doses of a TKI that may not be tolerated in clinical practice [23]. Moreover, even so-called dual-targeting of HER2 may not be sufficient to overcome resistance to HER2 inhibition, particularly in the case of HER2-amplified cancer with a PIK3CA mutation [16,24]. We have previously shown that, once resistance to HER2 inhibitors is established, inhibition of PI3K added to continued HER2 inhibition can overcome resistance [25].

In this work, we show that PIK3CA-activating mutations can be acquired during the development of resistance to HER2 inhibitors and that the presence of these mutations uncouples PI3K signaling from HER2. We further demonstrate that adding a PI3K inhibitor to dual-targeting of HER2 is more effective than HER2 targeting alone in a PI3K wild-type tumor and that the combination of HER2 and PI3K targeting is required for tumor regression in a model with $H E R 2$ amplification and PIK3CA mutation.

\section{Methods}

Cell cultures, inhibitor treatments and proliferation and apoptosis assays

BT474, SKBR3, MDA-MB-361, HCC1954 and UACC893 cells were obtained from the American Type Culture
Collection (Manassas, VA, USA). SUM190 cells were purchased from Asterand (Detroit, MI, USA). Lapatinibresistant (LR) cell lines were generated as described previously [25] and cultured in the presence of 1 to $2 \mu \mathrm{M}$ lapatinib. Lapatinib ditosylate and BIBW2992 were obtained from LC Laboratories (Woburn, MA, USA). BKM120 was obtained from Selleck Chemicals (Houston, TX, USA). Trastuzumab and pertuzumab were obtained from the Vanderbilt University Medical Center outpatient pharmacy. Unless otherwise noted, cells were treated with inhibitors at the following concentrations: lapatinib, $1 \mu \mathrm{M}$; trastuzumab, $10 \mu \mathrm{g} / \mathrm{ml}$; BKM120, $1 \mu \mathrm{M}$; and BIBW2992, $1 \mu \mathrm{M}$. Cell proliferation was measured using the sulforhodamine B (SRB) reagent. Cells plated in 96-well plates were treated with inhibitors and fixed in 1\% trichloroacetic acid after 72 hour treatment. Plates were rinsed with water and airdried, then stained with $0.4 \%$ SRB in $1 \%$ acetic acid. Excess stain was removed by washing with $1 \%$ acetic acid, and plates were air-dried. Stained cells were solubilized in $10 \mathrm{mM}$ Tris- $\mathrm{HCl}, \mathrm{pH} \mathrm{7.4}$, and absorbance at $590 \mathrm{~nm}$ was measured in a plate reader. Apoptosis was measured at 24 hours using the Caspase-Glo reagent (Promega, Madison, WI, USA) according to the manufacturer's instructions. For longer-term growth assays, cells were seeded into six-well plates and treated with inhibitors as indicated. Media and inhibitors were replenished twice weekly, and cells were grown for 2 to 3 weeks until confluence in the untreated wells. Cells were fixed and stained in $20 \%$ methanol with $0.5 \%$ crystal violet and washed with water. Dried plates were imaged on a flatbed scanner.

\section{Generation of PIK3CA mutant cells}

BT474 and SKBR3 parental cells were transduced with an amphotrophic retrovirus (LZRS) with neomycin resistance produced by Phoenix-AMPHO packaging cells containing C-terminal hemagglutinin (HA)-tagged bovine wild-type PIK3CA or E545K or H1047R mutations cloned from the JP1520 retroviral vector, as described previously [26]. To generate LR cell lines, transduced cells were treated with $1 \mu \mathrm{M}$ lapatinib for approximately 4 to 6 weeks. Wild-type PIK3CA-expressing cells did not survive selection. Mutant-expressing, lapatinib-selected cells were maintained in the presence of $1 \mu \mathrm{M}$ lapatinib.

\section{SNaPshot genotyping and Sanger sequencing}

Genomic DNA was isolated from parental and LR BT474 cells and analyzed by the SNaPshot mutational profiling method (SNaPshot; Vanderbilt, NY, USA). This assay involves multiplexed polymerase chain reaction (PCR) and multiplexed single-base primer extension, followed by capillary electrophoresis [27-29]; Vandana G Abramson et al., unpublished data. The current assay was designed to detect 18 somatic point mutations in three genes (Additional file 1: 
Table S1). Briefly, PCR primers were pooled to amplify the target DNA, and PCR was performed using the following conditions: $95^{\circ} \mathrm{C}$ (8 minutes), followed by 40 cycles at $\left(95^{\circ} \mathrm{C}\right.$ (20 seconds), $58^{\circ} \mathrm{C}$ (30 seconds) and $72^{\circ} \mathrm{C}$ (1 minute)) and then a final extension at $72^{\circ} \mathrm{C}$ (3 minutes) (Additional file 2: Table S2). Next, PAGE-purified primers were pooled together, and multiplex single-base extension reactions were performed on ExoSAP-IT-treated (USB/Affymetrix, Santa Clara, CA, USA) PCR products using the following conditions: $96^{\circ} \mathrm{C}$ (30 seconds), followed by 35 cycles at $\left(96^{\circ} \mathrm{C}\right.$ (10 seconds), $50^{\circ} \mathrm{C}$ (5 seconds) and $60^{\circ} \mathrm{C}$ (30 seconds)) (Additional file 3: Table S3). Extension products were applied to capillary electrophoresis in an ABI 3730 DNA Analyzer (Applied Biosystems, Foster City, CA, USA), and the data were interpreted using ABI GeneMapper software (version 4.0; Applied Biosystems). Human male genomic DNA (Promega) was used as a wild-type control. Spiking primers were mixed to create a pan-positive control mix for the assay (Additional file 4: Table S4).

To validate the SNaPshot result, exon 9 of PIK3CA was amplified by high-fidelity PCR from genomic DNA and sequenced by traditional Sanger sequencing methods. The primer sequences are as follows: 5'-TTCAGCAGT GTGGTAAAGTTC-3' forward; 5'GAGGCCAATCTTT TACCAAGC-3' reverse.

\section{Immunoblot analysis and p85 immunoprecipitation}

Cells were treated with inhibitors for 3 hours, and lysates were prepared as described previously [25]. Lysates were resolved on $7.5 \%$ acrylamide gels and transferred to Immobilon-FL PVDF (EMD Millipore, Billerica, MA, USA) and incubated in primary antibodies overnight at $4^{\circ} \mathrm{C}$. Blots were washed and incubated with infrared fluorescent dye secondary antibody conjugates (LI-COR Biosciences, Lincoln, NE, USA), and blots were imaged using a LI-COR Odyssey scanner. Antibodies from the following sources were used for analysis: pHER2 Y1248 (R\&D Systems, Minneapolis, MN, USA); Y877 pHER2 (Epitomics, Burlingame, CA, USA); Y1221/ 2 pHER2, Y11197 and Y1289 pHER3, S473 pAkt, Akt, S240/44 pS6, pErk1/2, Erk, and p110 $\alpha$ PI3K (Cell Signaling Technology, Danvers, MA, USA); p85 N-terminal Src homology 2 (SH2) domain (EMD Millipore); HA (Covance, Princeton, NJ, USA); actin (Sigma-Aldrich, St Louis, MO, USA); HER2 (Thermo Fisher, Pittsburgh, PA, USA); and glyceraldehyde 3-phosphate dehydrogenase (Santa Cruz Biotechnology, Santa Cruz, CA, USA).

To analyze $\mathrm{p} 110 \alpha$ isoforms bound to $\mathrm{p} 85$, lysates were prepared from wild-type or mutant-expressing cells and incubated with p85 rabbit antibody (directed against the $\mathrm{N}$-terminal $\mathrm{SH} 2$ domain) overnight at $4^{\circ} \mathrm{C}$ as described previously [30]. Antibody complexes were isolated with Dynabeads Protein A (Life Technologies) and washed. Beads were boiled in SDS sample buffer and resolved on polyacrylamide gels, then immunoblotted with HA, p110 $\alpha$ and p85 antibodies. Bands were quantitated using the LI-COR Odyssey scanner and Image Studio software. Mean values from triplicate experiments were compared by analysis of variance (ANOVA).

\section{Phosphoprotein ELISA analysis}

PathScan Sandwich ELISA kits for pHER2, pAkt and pS6 were purchased from Cell Signaling Technology and used according to the manufacturer's instructions. Lysates from cells treated with a range of lapatinib doses for 4 hours were prepared, and protein concentration determined by bicinchoninic acid assay (Pierce Biotechnology, Rockford, IL, USA). Lysates were diluted and incubated in enzyme-linked immunosorbent assay (ELISA) plates overnight at $4^{\circ} \mathrm{C}$, then washed and developed according to the protocol. Absorbance values were read on a BioTek Epoch microplate optical reader (BioTek, Winooski, VT, USA) and normalized for each experiment to values for untreated cells. ELISA experiments were repeated in triplicate. Mean values \pm SEM from the three experiments were used to plot $\log$ (inhibitor) vs. response curves using a variable slope model and to determine half-maximal inhibitory concentrations $\left(\mathrm{IC}_{50}\right)$ using GraphPad Prism software (GraphPad Software, La Jolla, CA, USA). For statistical analysis, $\mathrm{IC}_{50}$ values for each phosphoprotein were compared between wild-type and mutant cells by ANOVA.

\section{Xenograft experiments}

Animal studies were approved by the Vanderbilt University Medical Center Institutional Animal Care and Use Committee. BT-474 or HCC1954 cells (approximately $5 \times 10^{6}$ in $50 \%$ Matrigel) were injected into female athymic nude mice. For BT474 cells, mice were implanted with 60-day, 0.72-mg, slow-release estrogen pellets (Innovative Research of America, Sarasota, FL, USA) on the day prior to injection. After tumors reached $\geq 250 \mathrm{~mm}^{3}$, mice were randomly assigned to treatment with trastuzumab $(30 \mathrm{mg} / \mathrm{kg}$ by intraperitoneal injection twice weekly), lapatinib $(100 \mathrm{mg} / \mathrm{kg}$ by oral gavage daily) and/or BKM120 (30 mg/kg by oral gavage daily). Tumors were measured with calipersn and tumor volume in cubic millimeters was calculated by the formula length $/\left(2 \times\right.$ width $\left.^{2}\right)$. Mean tumor volumes for each treatment group are displayed on $\log _{2}$ scale. Kaplan-Meier curves were constructed using the time point at which tumor volumes exceeded $100 \mathrm{~mm}^{3}$.

\section{Results}

Acquired PIK3CA mutation in lapatinib-resistant cells

We previously showed that LR cells exhibit continued activation of PI3K signaling despite inhibition of the 
HER2 tyrosine kinase [25]. To identify mechanisms associated with maintenance of PI3K signaling in these drugresistant cells, we profiled them using the SNaPshot assay [27-29; Vandana G Abramson et al., unpublished] for a panel of mutations in PIK3CA, AKT and PTEN (Additional file 1: Table S1). Four of the six LR cell lines were derived from cells with preexisting hotspot PIK3CA mutations. None of the resistant cell lines acquired $A K T$ or PTEN mutations. However, BT-474 LR cells acquired an E542K PIK3CA mutation (Figure 1A). We confirmed the presence of this mutation in cDNA by Sanger sequencing. Parental cells did not have any detectable E542K mutant sequence. The mutation persisted in LR cells even after culture in the absence of lapatinib for more than 2 weeks (Figure 1B). The E542 mutation is unique to BT474 cells. Other HER2-amplified cell lines known to contain PIK3CA mutations have either an E545K or H1047R mutation [10,14].

PIK3CA mutation partially uncouples HER2 inhibition for phosphoinositide 3-kinase signaling

We observed that the four HER2-amplified cell lines that contain de novo PIK3CA mutations develop resistance to lapatinib more rapidly than PIK3CA wild-type cells in chronic cell culture. Thus, because the BT474 cells acquired a PIK3CA mutation upon the development of lapatinib resistance, we reasoned that the gain of function conferred by this mutation in $\mathrm{p} 110 \alpha$ uncouples downstream PI3K signaling from HER2 and thereby blunts the inhibitory effect of lapatinib. We first evaluated response to lapatinib in parental and LR BT474 cells. Resistant cells were cultured in the absence of

\section{A BT474 Parental}

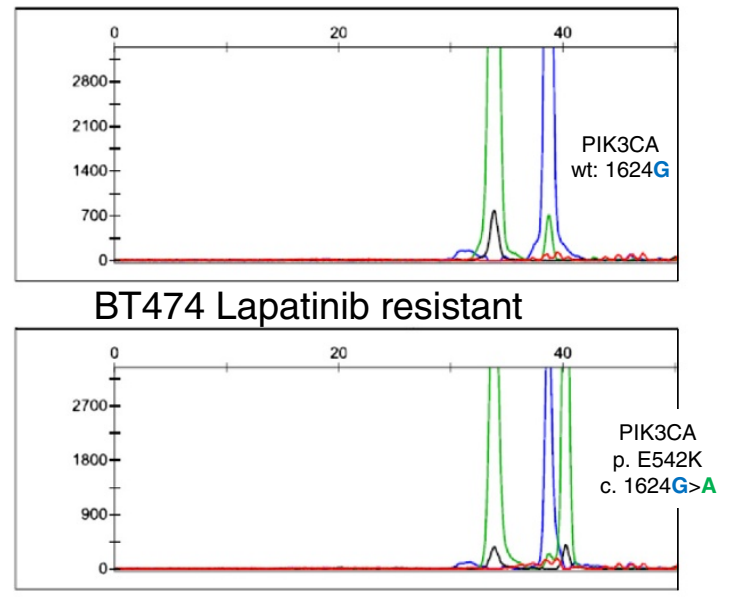

B

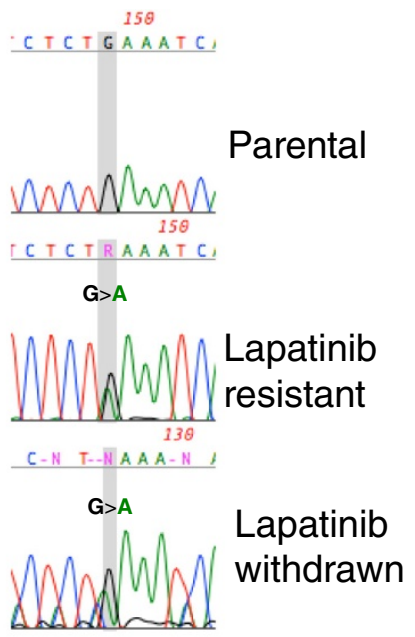

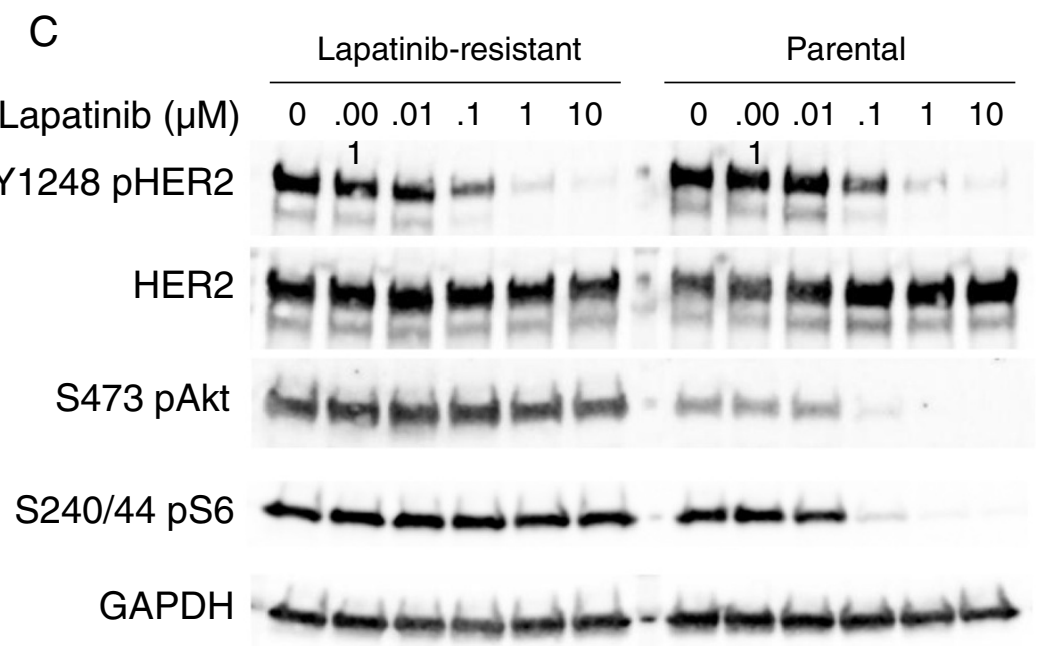

Figure 1 BT474 lapatinib-resistant cells acquire E542K PIK3CA mutation. (A) SNaPshot analysis of genomic DNA isolated from parental and lapatinib-resistant (LR) cells reveals a distinct peak corresponding to a G1624A nucleotide change in resistant cells. (B) Sanger sequencing of exon 9 of PIK3CA confirms the presence of the G1624A nucleotide change in LR cells. (C) Lysates from parental and LR cells treated with increasing doses of lapatinib, ranging from 0.001 to $10 \mu \mathrm{M}$, were analyzed by immunoblotting with the indicated antibodies. 


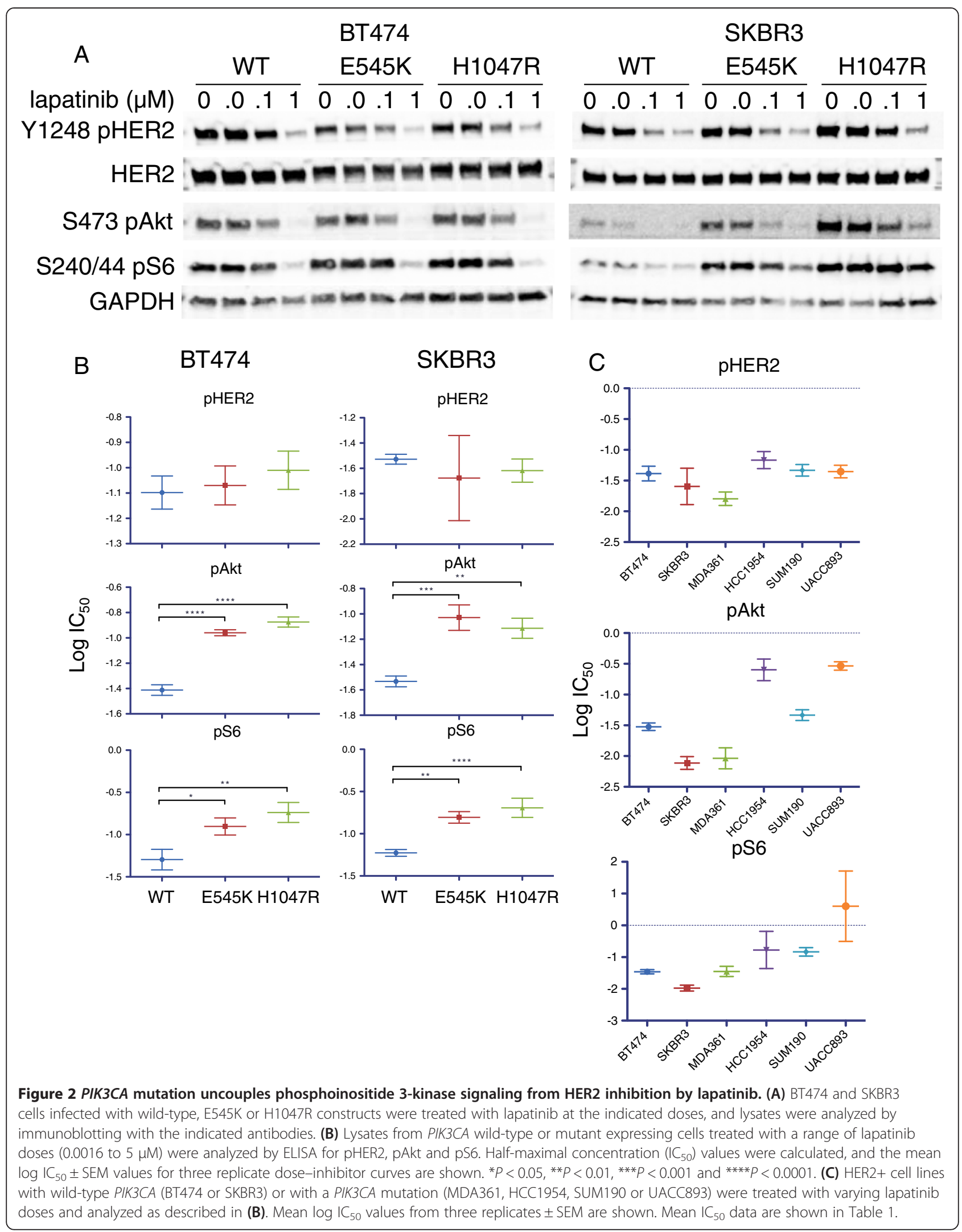


lapatinib for at least 2 weeks until recovery of HER2 phosphorylation was observed. After treatment of cells with increasing doses of lapatinib, we observed a similar inhibition of HER2 phosphorylation in parental and resistant cells, but the resistant cells with an acquired E542K mutation showed only very limited inhibition of PI3K signaling as measured by Akt and S6 phosphorylation (Figure 1C).

We next transduced parental BT474 and SKBR3 cells with wild-type, E545K or H1047R PIK3CA retroviral constructs. Expression of the ectopic p110 $\alpha$ construct was verified by Western blot analysis for a C-terminal HA-tag (Additional file 5: Figure S1). We then evaluated the inhibition of pHER2 and PI3K signaling with a range of lapatinib doses. Similarly to BT474 LR cells with acquired E542K mutation, cells with the other hotspot mutations showed a blunted inhibitor response of PI3K signaling to lapatinib with persistent PI3K-Akt signaling (Figure 2A).

To better quantify the signaling output of mutant PIK3CA in cells in which HER2 was inhibited, we measured pHER2 by ELISA in cells treated with lapatinib and compared the $\mathrm{IC}_{50}$ for HER2 inhibition to the $\mathrm{IC}_{50}$ for PI3K inhibition as measured by Akt S473 and S6 S240/244 phosphorylation. We first compared BT474 and SKBR3 cells (without endogenous hotspot mutations) infected with wild-type, E545K or H1047R p110 $\alpha$ retroviral constructs. As expected, $\mathrm{IC}_{50}$ data for inhibition of HER2 by lapatinib were similar between wildtype and PIK3CA mutant expressing cells (Figure 2B). However, both cell lines expressing either mutant PIK3CA isoform showed a significant increase in the
$\mathrm{IC}_{50}$ for both Akt and S6 phosphorylation (Figure 2B and Additional file 6: Figure S2). For cells expressing ectopic mutant PI3K, the increase in $\mathrm{IC}_{50}$ was typically two- to threefold higher for the mutant cells than for the wild-type cells (Table 1). Interestingly, we observed a similar increase in the $\mathrm{IC}_{50}$ for pAkt and pS6 in the LR BT474 cells with an acquired E542K mutation (Additional file 7: Figure S3). These data suggest that mutant $\mathrm{p} 110 \alpha$ uncouples PI3K signaling from HER2.

We next tested whether a similar partial uncoupling of PI3K signaling from HER2 activation was occurring in cells with endogenous PI3K hotspot mutations. We measured the $\mathrm{IC}_{50}$ values for HER2 and PI3K inhibition in four cell lines with endogenous PIK3CA mutations and compared them to the data for BT474 and SKBR3 cells. Again, we observed similar magnitudes of inhibition of HER2, but cell lines with endogenous PI3K mutations, particularly H1047R, showed an increased $\mathrm{IC}_{50}$ for pAkt and, in one cell line, for pS6 (Figure 2C and Additional file 8: Figure $\mathrm{S4})$. There was a trend toward increased $\mathrm{IC}_{50}$ for inhibition of S6 phosphorylation by lapatinib, but the difference was not statistically significant. We observed in the dose-response curves that the level of the remaining S6 phosphorylation, even at maximal $(5 \mu \mathrm{M})$ doses of lapatinib, was higher than that of wild-type cells (Additional file 8: Figure S4). This finding confirms that cell lines with endogenous PI3K mutations have a blunted inhibitory response and explains in part how resistance to lapatinib may emerge more quickly in PIK3CA mutant cells.

Table 1 Mean half-maximal inhibitory concentrations for lapatinib inhibition of HER2 and signaling proteins in PIK3CA mutant cells ${ }^{\mathrm{a}}$

\begin{tabular}{|c|c|c|c|c|c|}
\hline & HER2 & Akt & Increase over WT & S6 & Increase over WT \\
\hline BT474 & 0.0411 & 0.0300 & & 0.0347 & \\
\hline BT474 LR & 0.0204 & 0.3925 & 13.1 & 0.7863 & 22.7 \\
\hline BT474 wt & 0.0798 & 0.0387 & & 0.0506 & \\
\hline BT474 E545K & 0.0852 & 0.1098 & 2.8 & 0.1251 & 2.5 \\
\hline BT474 H1047R & 0.0978 & 0.1336 & 3.4 & 0.1829 & 3.6 \\
\hline SKBR3 & 0.0254 & 0.0077 & & 0.0106 & \\
\hline SKBR3 wt & 0.0297 & 0.0293 & & 0.0593 & \\
\hline SKBR3 E545K & 0.0211 & 0.0936 & 3.2 & 0.1563 & 2.6 \\
\hline SKBR3 H1047R & 0.0241 & 0.0770 & 2.6 & 0.2028 & 3.4 \\
\hline MDA361 & 0.0160 & 0.0092 & 0.5 & 0.0354 & 1.6 \\
\hline HCC1954 & 0.0681 & 0.2527 & 13.4 & 0.1678 & 7.4 \\
\hline SUM190 & 0.0465 & 0.0464 & 2.5 & 0.1461 & 6.5 \\
\hline UACC893 & 0.0444 & 0.2920 & 15.5 & 4.0040 & 177.0 \\
\hline
\end{tabular}

${ }^{\mathrm{a}} \mathrm{WT}$, Wild type. Half-maximal inhibitory concentration $\left(\mathrm{IC}_{50}\right)$ values for inhibition of HER2, Akt and S6 phosphorylation by lapatinib treatment were determined by enzyme-linked immunosorbent assay (dose-response curves are shown in Additional file 6: Figure S2, Additional file 7: Figure S3 and Additional file 8: Figure S4). Mean $\mathrm{IC}_{50}$ values derived from at least three separate experiments are shown. For phosphoinositide 3-kinase signaling proteins $A$ kt and $\mathrm{S} 6$, $\mathrm{IC}_{50}$ values from cells with PIK3CA mutations were compared to average values for cells without hotspot mutations (BT474 and SKBR3). 


\section{Lapatinib-resistant cells preferentially utilize H1047R mutant PIK3CA}

We reasoned that cells that developed resistance to lapatinib by exploiting the uncoupling of PI3K from HER2 inhibition to allow escape from that inhibition would rely on the gain of function conferred by the mutant $\mathrm{p} 110 \alpha$ isoform to allow for continued signaling in the presence of lapatinib. Thus, after selection for resistance, we hypothesized that the pool of p110 $\alpha$ in complex with p85 and available for PI3K signaling would contain more mutant $\mathrm{p} 110 \alpha$ than that available before selection for resistance. To test this hypothesis, BT474 and SKBR3 cells expressing ectopic HA-tagged E545K or H1047R p110 $\alpha$ were selected for lapatinib resistance for 4 to 6 weeks. After an initial period of slower growth, the lapatinibselected cells proliferated. We observed continued inhibition of HER2 by lapatinib, but recovery of Akt and S6 phosphorylation (Figure 3A). In LR cells, PI3K-Akt signaling was still dependent on $\mathrm{p} 110 \alpha$ catalytic activity, as treatment with the PI3K inhibitor BKM120 abolished S473 Akt phosphorylation in both parental and LR ectopic PIK3CA mutant-expressing cells (Figure 3B).

We hypothesized that the gain of function conferred by the mutant $\mathrm{p} 110 \alpha$ isoform in the LR cells would result in the preferential engagement of the mutant isoform for PI3K signaling under the selective pressure of HER2 inhibition. As an indirect measure of this utilization of mutant PI3K, we tested whether the PI3K signaling complex in the LR cells would be enriched for the mutant $\mathrm{p} 110 \alpha$ isoform. We immunoprecipitated the pool of p110 $\alpha$ in a complex with p85 using a p85 antibody and evaluated the level of mutant isoform present before and after lapatinib selection by immunoblotting for the HA-tag. In BT474 cells, we observed that more of the H1047R mutant $\mathrm{p} 110 \alpha$ was detected in a complex with p85 in resistant cells than in parental cells (Figures 3C and 3D). We found a similar increase in HA expression in p85 immunoprecipitates from SKBR3 cells expressing H1047R p110 $\alpha$, but this increase did not persist after normalizing for levels of immunoprecipitated p85 (Figure 3D and Additional file 9: Figure S5). We did not observe any increase in levels of the E545K mutant in a complex with p85 in either cell line. The E545K mutation has been proposed to alter interaction with p85 and so may have a different mechanism of action than the H1047R catalytic site mutation [12,31]. This may explain why levels of E545K mutant p110 $\alpha$ did not increase in PI3K from LR cells.

\section{HER2 inhibitor resistance conferred by phosphoinositide} 3-kinase mutation is susceptible to p110a inhibition

The data we compiled in this study suggest that the gain of function conferred by PIK3CA mutations partially uncouples PI3K signaling from HER2 and allows for eventual escape from HER2 inhibition, but that signaling remains susceptible to inhibitors of p110 $\alpha$. This idea is in agreement with previous reports that lapatinib resistance from PI3K mutations or PTEN loss could be overcome by combining lapatinib with a dual PI3K/ mammalian target of rapamycin (PI3K/mTOR) inhibitor [16]. Another possibility is that the gain of function of mutant PI3K can amplify low levels of HER2 signaling that remain after single-inhibitor treatment of HER2+ breast cancer [23], but the combination of dual HER2 inhibitor blockade may reduce this low level of signaling and thus inhibit even PIK3CA mutant cancers. This idea is consistent with recent clinical data indicating that the combination of trastuzumab and lapatinib or trastuzumab and pertuzumab is more effective than single HER2 inhibitor therapy [20-22]. To test whether additional HER2 blockade could overcome resistance to singleagent lapatinib or trastuzumab conferred by PI3K mutation, we treated LR PIK3CA mutant cells with lapatinib and trastuzumab and with or without the PI3K inhibitor BKM120. We found that the addition of trastuzumab did not inhibit the already low level of HER2 phosphorylation or further diminish the minimally detectable HER3 phosphorylation in these cells, nor did it further decrease PI3K-Akt signaling through Akt or S6 phosphorylation (Figure 4A). This low level of signaling appears to be sufficient for cell proliferation, as ectopic PI3K expression allowed for continued proliferation of cells in the presence of both trastuzumab and lapatinib (Additional file 10: Figure S6). Only the addition of the PI3K inhibitor resulted in PI3K pathway inhibition (Figure 4A). We also tested the addition of pertuzumab, a monoclonal antibody against HER2 that recognizes a different epitope than trastuzumab, and BIBW2992, a covalent inhibitor of EGFR/HER2 RTKs. None of these additional HER2 inhibitors resulted in any decrease in cell proliferation or increase in apoptosis in LR cells; only the addition of PI3K inhibition resulted in decreased proliferation and the induction of apoptosis (Figures $4 \mathrm{~B}$ and $4 \mathrm{C}$ ).

\section{HER2 inhibitors in combination with phosphoinositide 3-kinase inhibitors can prevent outgrowth of resistant tumors}

Because we did not find any benefit associated with additional HER2 inhibitors once resistance to an HER2 inhibitor was established in cell culture, we sought to test whether addition of a PI3K inhibitor to the combination of lapatinib and trastuzumab would prevent the outgrowth of resistant tumors, both with and without PI3K mutations. We first used BT474 cells (without PI3K hotspot mutations). As previously reported [32], trastuzumab and lapatinib together induced BT474 tumor regression. Treatment with BKM120 alone was able to block tumor growth, but did not induce any tumor 


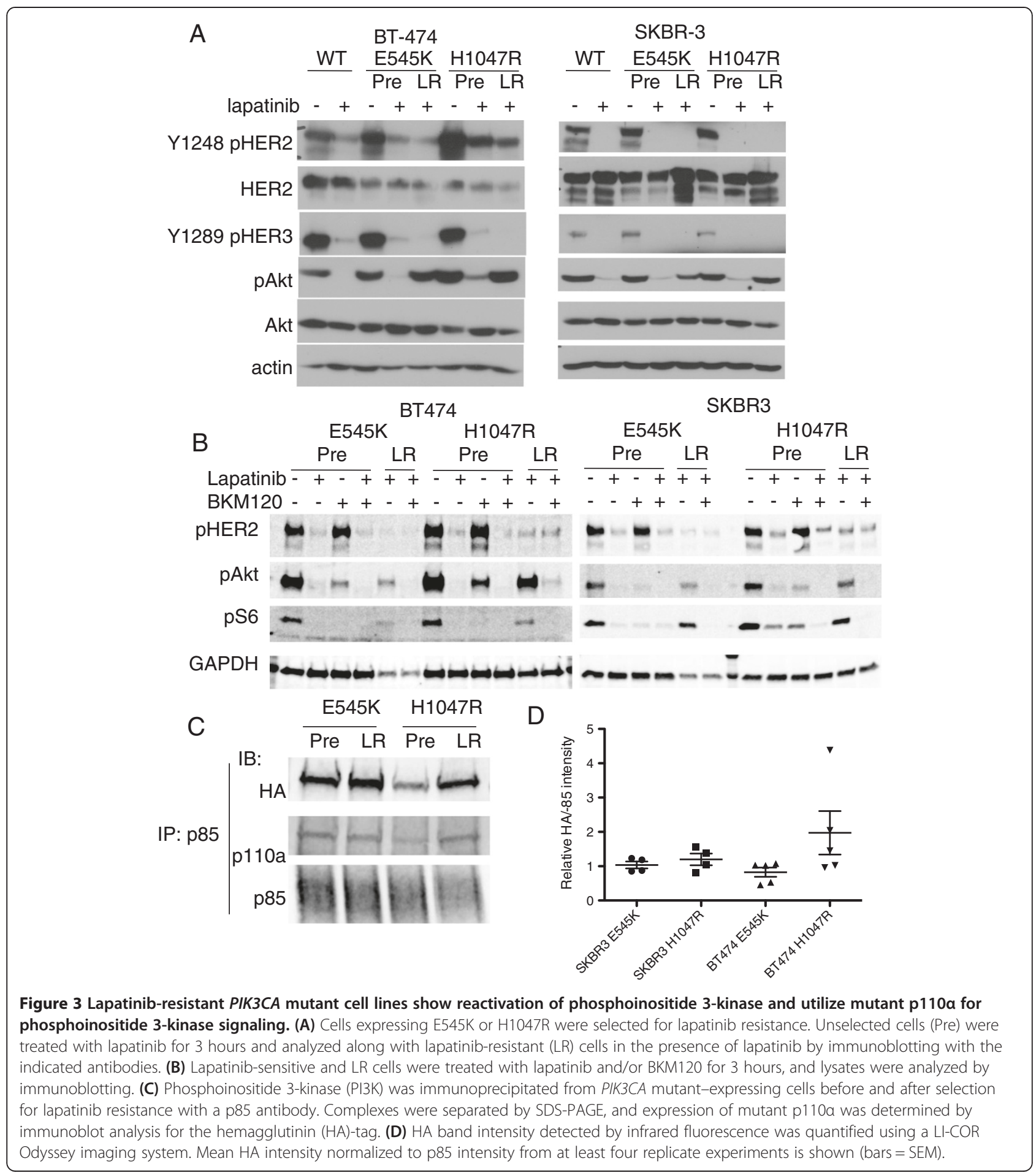

regression. Combination of a single inhibitor of HER2 with a PI3K inhibitor appeared to be somewhat effective at inducing tumor regression, with a magnitude of benefit similar to the trastuzumab/lapatinib combination. Only the combination of all three drugs was sufficient to induce a robust regression in tumor growth, however, such that all of the mice in the treatment group showed complete regression of tumor growth after about 3 weeks of treatment (Figure 5B). At the end of 4 weeks of treatment, only residual tumors in the BKM120-only or dual-therapy groups were available for analysis, and we observed blockade of PI3K-Akt signaling by the PI3K inhibitor in these residual tumors (Additional file 11: Figure S7). Although the combination of all 


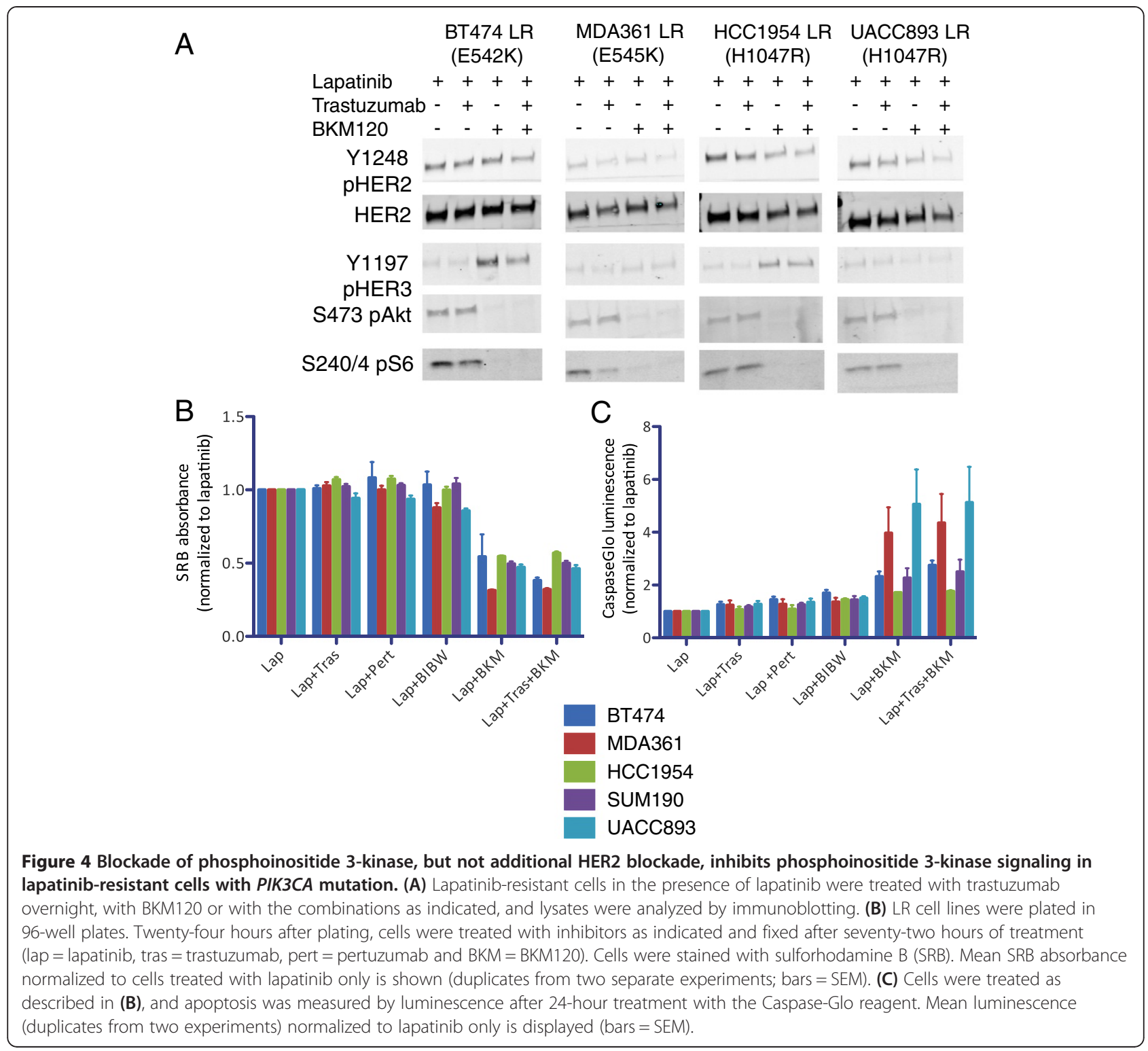

three drugs was better able to induce tumor regression than two-drug combinations, there were some mice in each group with complete tumor regression with dual- or triple-therapy. To determine whether the response to all three drugs was more durable than two-drug combinations, we followed mice after 28 days of treatment for tumor regrowth. Tumors recurred more rapidly in the trastuzumab/lapatinib combination-treated group, although all groups had at least one mouse with recurrent tumor growth. In all cases where significant recurrence was observed, retreatment with the combination of all three drugs appeared to be effective (black arrows in Figure 5C).

We next tested the combination of HER2 and PI3K inhibition in a xenograft model of HCC1954 cells with endogenous an H1047R PIK3CA mutation. These tumors showed continued growth in the presence of trastuzumab or lapatinib as single agents, further suggesting that PIK3CA mutations confer resistance to HER2 inhibitors (Figure 5D). In these tumors, the combination of trastuzumab and lapatinib was unable to induce tumor regression as it did in BT474 xenografts. BKM120 alone was as effective at inhibiting growth as dual HER2 inhibition, but the combination of HER2 and PI3K inhibitors was required to induce tumor regression. Unlike treatment of HER2+/PIK3CA wild-type tumors, no complete regressions were observed in any treatment group, though most tumors in the triple-therapy group remained only barely palpable at the end of treatment. After 28 days, treatment was stopped and mice were again followed for tumor recurrence, which eventually developed in about half of the mice (Figure 5E). Retreatment with all three 


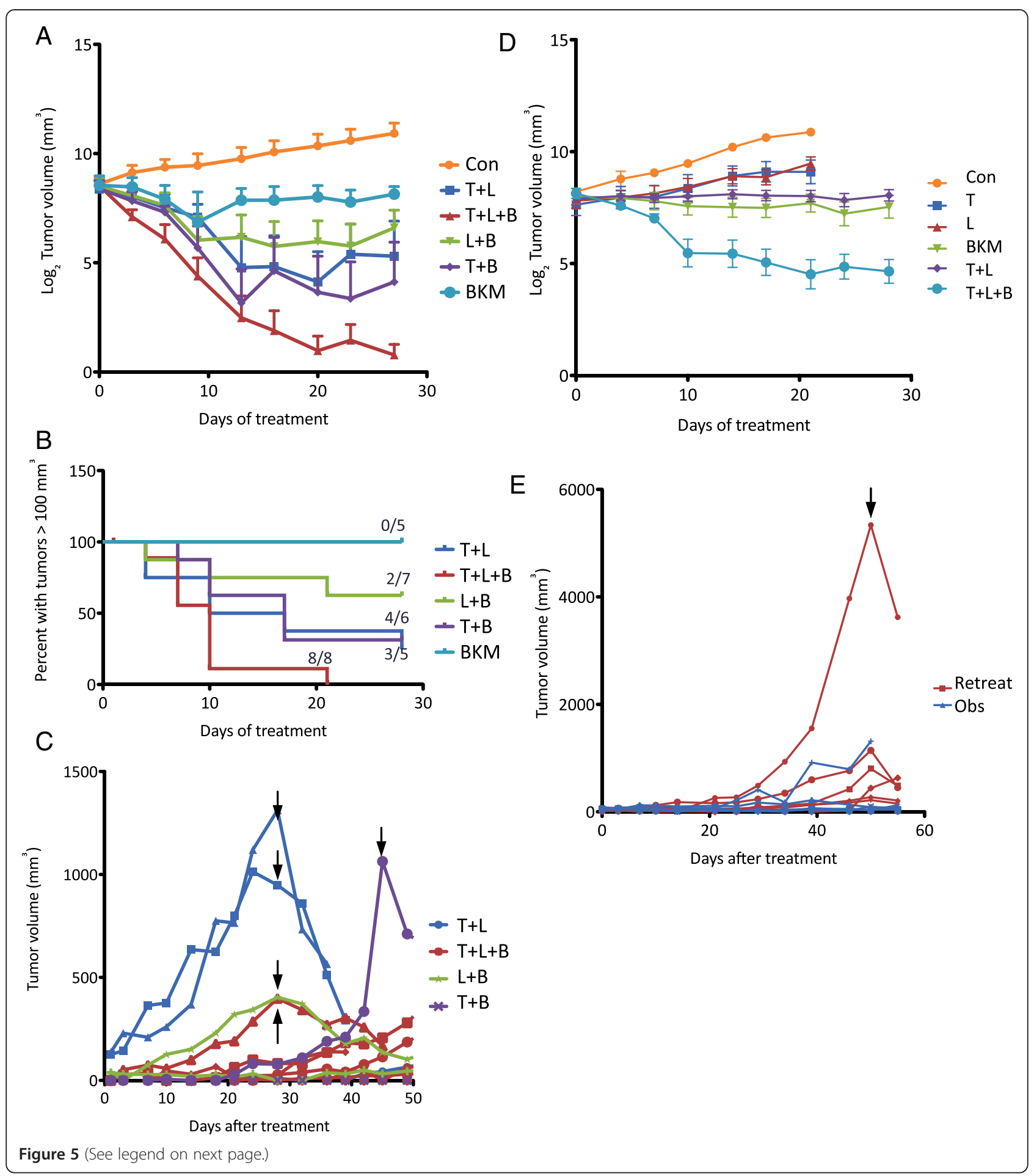


(See figure on previous page.)

Figure 5 Phosphoinositide 3-kinase inhibition combined with HER2 inhibition is more effective at inducing tumor regression than HER2 inhibition alone. (A) Mice were injected with BT474 cells, and, after tumor formation, mice were treated with trastuzumab ( $T$ ), lapatinib ( $L$ ) or BKM120 (B) in the combinations indicated. Tumor growth was measured twice weekly. The log 2 tumor volume data is shown over the 28-day treatment course (bars =SEM). (B) Kaplan-Meier plot showing the number of mice in each treatment group whose tumors regressed to below $100 \mathrm{~mm}^{3}$ in volume during treatment. The number of responses and the total number in each group are displayed above the curve. (C) After 28 days of treatment, mice whose tumors had regressed were followed for recurrence. Tumor volume for individual mice is plotted with the color according to the initial treatment group. Arrows indicate retreatment with $T+L+B$. (D) Mice were injected with HCC1954 cells (H1047R PIK3CA mutant), and, after tumor formation, mice were treated with trastuzumab (T), lapatinib (L) or BKM120 (B) alone or in the combinations indicated. Tumor growth was measured twice weekly. The $\log _{2}$ tumor volume data are shown over the 28-day treatment course (bars = SEM). Control, $T$ and $L$ alone mice were killed at day 21 of treatment because of excessive tumor volume. (E) After 28 days of treatment, mice from the $T+L+B$ group whose tumors had regressed were followed for recurrence. Tumor volumes for individual mice are plotted. Red indicates mice whose tumors regrew, and those retreated with $T+L+B$ are indicated by the arrow.

inhibitors was able to reinduce tumor regression, suggesting that tumors remain sensitive to the combination of all three drugs. These results imply that a longer duration of treatment would be necessary to induce complete regression in tumors with the PIK3CA mutation.

\section{Discussion}

The importance of the PI3K-Akt axis in oncogenic signaling is becoming increasingly apparent, especially in the case of HER2+ breast cancer, where inhibition of PI3K signaling is critical for the antitumor action of HER2 inhibitors and activating mutations in the PI3K pathway can confer resistance to HER2 inhibitors. We show in our present study that acquisition of a hotspot PIK3CA mutation is a mechanism of acquired resistance to lapatinib and that PIK3CA mutations partially uncouple PI3K from HER2 to allow for the development and maintenance of resistance. Further, targeting of PI3K itself, in combination with maximal HER2 blockade with both an antibody and a TKI, is more effective than HER2 targeting alone for HER2 tumors without PIK3CA mutations and is required for HER2 tumors with $P I K 3 C A$ mutations.

We and others have found that both helical and catalytic domain mutations of PIK3CA can confer resistance to HER2 inhibitors $[7,16,24,33]$. In our biochemical assays, ectopic expression of either mutation appeared to uncouple HER2 inhibition from PI3K signaling to a similar degree (Figure 2), and cells expressing either mutation showed reactivation of PI3K upon the development of resistance [25]. When we assayed resistant cells for the proportion of mutant vs. wild-type p110 $\alpha$ in the PI3K signaling complex compared to sensitive cells, however, we observed an increase in utilization of the H1047R mutant isoform but not the E545K isoform. We also did not observe the same degree of uncoupling of downstream signaling in a cell line with endogenous E545K compared with H1047R expressing cell lines (Figure 2). This is consistent with different proposed mechanisms for these mutations, whereby the helical domain mutant may function primarily to abolish the normal regulatory inhibition of PI3K, whereas the increased catalytic activity conferred by the kinase domain mutation may be required by the mutant cells still under the selective pressure of HER2 inhibition [12,31]. In either case, catalytic inhibition of $\mathrm{p} 110 \alpha$ was effective at blocking downstream signaling for both mutations.

This catalytic inhibition of $\mathrm{p} 110 \alpha$ is emerging as an attractive possible therapeutic option, with a number of inhibitors currently in preclinical and clinical development [34]. Several studies have investigated the potential importance of PI3K inhibition as a therapeutic strategy in HER2-amplified breast cancer, but these studies have uncovered feedback loops and other factors that may limit the use of PI3K inhibitors as single agents. A p110specific inhibitor, GDC-0941, inhibited the growth of HER2-amplified cells in culture, but the combination of GDC-0941 with trastuzumab was required for tumor growth inhibition in mice [7]. Interestingly, the combination of GDC-0941 with antibody inhibitors of HER2 (trastuzumab and pertuzumab) appeared to be more effective than GDC-0941 in combination with a TKI [35]. In HER2+ cells with PIK3CA mutations, low doses of lapatinib are ineffective, but the cells are susceptible to dual PI3K/mTOR inhibitors such as BEZ235 [16] or INK-128 [36]. In the latter study, however, combination of the HER2 TKI with the PI3K inhibitor was not able to induce tumor regression, whereas combination of a PI3K p110 inhibitor (BKM120) with trastuzumab did result in tumor regression, albeit in a wild-type PIK3CA model. In a transgenic HER2+/PIK3CA H1047R mutant mouse model, tumors that were resistant to the combinations of trastuzumab and lapatinib or trastuzumab and pertuzumab could be inhibited by BKM120 alone or in combination with HER2 inhibitors [24]. Those observations are in agreement with our present findings that BKM120 alone did not induce tumor regression, but did result in tumor regression when combined with HER2 inhibitors. This increased efficacy of HER2 and PI3K inhibitor combinations may be partly explained by increased Erk signaling and feedback upregulation of HER3 after PI3K inhibitor treatment alone, whereas 
targeting HER2 in combination with PI3K inhibition could overcome these compensatory mechanisms $[37,38]$.

Our results support the clinical testing of combinations of PI3K inhibition with maximal HER2 inhibition for HER2+ breast cancer. In biomarker studies from the recent CLEOPATRA clinical trial, although the combination of trastuzumab and pertuzumab was superior to trastuzumab alone, regardless of PIK3CA mutation status, the magnitude of benefit was less for those tumors with PIK3CA mutations than for wild-type tumors [39]. There is a potential for overlapping toxicities when combining multiple inhibitors, so important questions regarding selection of patients and the sequence and timing of combination therapies remain to be addressed. Our data suggest that PIK3CA mutation can be acquired during HER2 inhibitor treatment and that the presence of a PIK3CA mutation requires PI3K blockade in addition to HER2 blockade. Despite several lines of preclinical evidence that either PIK3CA mutation can confer HER2 inhibitor resistance, a robust correlation of the occurrence of PIK3CA mutations with outcomes after trastuzumab or lapatinib therapy in patients is still lacking. A recent study of PTEN expression and PIK3CA mutation in HER2+ patients with either recurrent disease after trastuzumab treatment or progression of metastatic disease while on trastuzumab therapy showed a significantly increased frequency of either PTEN loss or PIK3CA mutation compared to untreated HER2+ tumors, but PIK3CA mutation status alone did not appear to be significantly enriched in the clinically trastuzumab-refractory cohort [19]. In addition to determining whether PIK3CA mutation predicts for the eventual development of resistance, there is a critical need to understand how frequently PIK3CA mutations occur after patients develop resistance to HER2 inhibitor treatment. Another important question is whether these combinations need to be given together as part of the initial treatment or whether direct PI3K inhibition can be added after therapeutic resistance develops. In all of our models of resistance, we found reactivation of PI3K signaling and susceptibility to PI3K inhibition. We also found that additional HER2 blockade after the development of lapatinib resistance was ineffective and that PI3K inhibition was essential to overcoming resistance. This suggests that a potentially better-tolerated sequential approach might be effective, and, indeed, sequential additive treatment with HER2 inhibitors appears to have some clinical efficacy, though these patients eventually develop resistance to combined HER2 blockade [21]. In our xenograft models, however, we found that up-front combination of both HER2 and PI3K blockade was most effective at inducing regression and preventing tumor regrowth, regardless of PI3K mutation status. In the case of PIK3CA mutation, this combination was required to induce tumor regression. This suggests that the combination of HER2 and PI3K therapies up front, if tolerable, might provide optimal treatment for patients with PIK3CA mutations and also have potential benefits for patients with PIK3CA wild-type tumors.

\section{Conclusions}

Our results show that the gain of function conferred by PIK3CA mutations contributes to resistance to HER2 inhibitors by partially uncoupling PI3K signaling from HER2 inhibition. They also show that, though maximal HER2 blockade is insufficient to overcome the effects of the mutation, addition of a PI3K inhibitor to HER2 inhibitors can reverse or prevent resistance. This suggests that this combination may be an effective strategy to overcome resistance in patients that warrants clinical testing.

\section{Additional files}

Additional file 1: Table S1. The breast cancer SNaPshot screen queries 18 point mutations in 3 genes.

Additional file 2: Table S2. Breast cancer SNaPshot screen multiplex polymerase chain reaction primers.

Additional file 3: Table S3. Single-base extension primers for the breast cancer SNaPshot screen.

Additional file 4: Table S4. Breast SNaPshot screen spiking primers used for pan-positive control assay.

Additional file 5: Figure S1. Expression of ectopic PIK3CA constructs. Lysates from parental cells or cells infected with wild-type, E545K (EK) or H1047R (HR) PIK3CA retroviral constructs were analyzed by immunoblotting with the indicated antibodies. The PIK3CA constructs contain a C-terminal hemagglutinin (HA)-tag.

Additional file 6: Figure S2. Phosphoinositide 3-kinase (PI3K) mutation shifts the half-maximal inhibitory concentration for lapatinib inhibition of $\mathrm{PI3K}$ signaling. Cells expressing wild-type or mutant PI3K constructs were treated with a range of lapatinib concentrations (0.0016 to $5 \mu \mathrm{M})$ and pHER2, pAkt and pS6 measured by enzyme-linked immunosorbent assay. Results were normalized to untreated cells and inhibitor response curves were fitted with GraphPad from a mean of three experiments (bars =SEM).

Additional file 7: Figure S3. Acquired E542K mutation in BT474 lapatinib resistant cells shifts the lapatinib half-maximal inhibitory concentration $\left(\mathrm{IC}_{50}\right)$ for phosphoinositide 3-kinase signaling. BT474 parental or lapatinib-resistant cells cultured without lapatinib for at least 2 weeks were treated with a range of lapatinib doses and analyzed by enzyme-linked immunosorbent assay for pHER2, pAkt and pS6. The inhibitor response curves and mean $I C_{50}$ values from three separate experiments are displayed (bars = SEM).

Additional file 8: Figure S4. Cell lines with endogenous phosphoinositide 3-kinase (PI3K) mutations show uncoupling of PI3K signaling from HER2 inhibition by lapatinib. (A) Cell lines (wild-type or with PI3K mutations as indicated) were treated with a range of lapatinib doses and analyzed by enzyme-linked immunosorbent assay for pHER2, pAkt and pS6. The inhibitor response curves derived from a mean of three separate experiments are shown. (B) The level of pS6 remaining at the $5 \mu \mathrm{M}$ lapatinib dose, normalized to untreated cells, is shown (mean \pm SEM)

Additional file 9: Figure S5. Lapatinib-resistant cells utilize H1047R mutant PIK3CA for phosphoinositide 3-kinase (PI3K) signaling. Cells infected with E545K or H1047R mutant PIK3CA vectors were selected for lapatinib resistance. PI3K was immunoprecipitated from cells before and after selection for resistance, and the level of hemagglutinin (HA) expression was determined by immunoblot analysis of the immune complexes. 
HA band intensity was quantitated using infrared fluorescence secondary antibodies and LI-COR software. The relative intensity of HA expression in resistant cells compared with their unselected counterparts is shown. The mean value $( \pm$ SEM) of five or six replicate immunoprecipitations is displayed.

Additional file 10: Figure S6. Phosphoinositide 3-kinase (PI3K) mutation allows for emergence of resistant colonies, even to dual HER2 blockade. Cells expressing wild-type or PI3K mutations as indicated were seeded into 12-well plates and were treated with lapatinib, trastuzumab or a combination of the two 24 hours after plating as indicated. Cells were grown for 2 to 3 weeks in media, and drugs were replenished twice weekly. At the end of treatment, the cells were fixed and stained with crystal violet.

Additional file 11: Figure S7. BKM120 is required to maximally inhibit phosphoinositide 3-kinase signaling in tumor xenografts. Tumors from BT474 cells that remained after 28 days of treatment with BKM120 (B), lapatinib (L) or trastuzumab (T) in the combinations indicated were harvested, and lysates were prepared and analyzed by immunoblotting with the indicated antibodies.

\section{Abbreviations}

ANOVA: Analysis of variance; EGFR: Epidermal growth factor receptor; ELISA: Enzyme-linked immunosorbent assay; HER2: Human epidermal growth factor receptor 2; HER3: Human epidermal growth factor receptor 3; $I_{50}$ : Half-maximal inhibitory concentration; LR: Lapatinib-resistant; PCR: Polymerase chain reaction; PI3K: Phosphoinositide 3-kinase; PIK3CA: Phosphoinositide 3-kinase catalytic subunit a; RTK: Receptor tyrosine kinase; SRB: sulforhodamine B; TKI: Tyrosine kinase inhibitor.

\section{Competing interests}

The authors declare that they have no conflicts of interest.

\section{Authors' contributions}

BR and CLA conceived and designed experiments. BR and SC performed experiments and analyzed data. KD contributed the SNapShot assay and acquired and interpreted the SNaPshot data. BR and CLA drafted the manuscript. All authors read and approved the final version of the manuscript.

\section{Acknowledgements}

This work was supported by the following: R01 grant CA80195 (CLA), ACS Clinical Research Professorship Grant CRP-07-234 (CLA), Breast Cancer Specialized Program of Research Excellence (SPORE) P50 CA98131, and Vanderbilt-Ingram Cancer Center Support Grant P30 CA68485; DOD Breast Cancer Research Program post-doctoral award BC087465 (BNR) and NCI K08 CA143153 (BNR). The breast cancer SNaPshot screen was performed in the Vanderbilt Innovative Translational Research Shared Resource supported by the Vanderbilt-Ingram Cancer Center and the TJ Martell Foundation. Technical assistance was provided by Donald Hucks, MS

\section{Author details}

'Division of Hematology-Oncology, Department of Medicine, School of Medicine, Vanderbilt University, 2220 Pierce Avenue, 777 PRB, Nashville, TN 37232-6307, USA. ${ }^{2}$ Department of Cancer Biology, Vanderbilt University, 2220 Pierce Avenue, 777 PRB, Nashville, TN 37232-6307, USA. ${ }^{3}$ Breast Cancer Research Program, Vanderbilt-Ingram Cancer Center, 2220 Pierce Avenue, 777 PRB, Nashville, TN 37232-6307, USA. ${ }^{4}$ Vanderbilt-Ingram Cancer Center, Vanderbilt University, 2220 Pierce Avenue, 777 PRB, Nashville, TN 37232-6307, USA.

Received: 27 September 2013 Accepted: 10 January 2014 Published: 23 January 2014

\section{References}

1. Geyer CE, Forster J, Lindquist D, Chan S, Romieu CG, Pienkowski T, JagielloGruszfeld A, Crown J, Chan A, Kaufman B, Skarlos D, Campone M, Davidson N, Berger M, Oliva C, Rubin SD, Stein S, Cameron D: Lapatinib plus capecitabine for HER2-positive advanced breast cancer. N Engl I Med 2006, 355:2733-2743.
2. Slamon DJ, Leyland-Jones B, Shak S, Fuchs H, Paton V, Bajamonde A, Fleming T, Eiermann W, Wolter J, Pegram M, Baselga J, Norton L: Use of chemotherapy plus a monoclonal antibody against HER2 for metastatic breast cancer that overexpresses HER2. N Engl J Med 2001, 344:783-792.

3. Yarden Y, Sliwkowski MX: Untangling the ErbB signalling network. Nat Rev Mol Cell Biol 2001, 2:127-137.

4. Holbro T, Beerli RR, Maurer F, Koziczak M, Barbas CF 3rd, Hynes NE: The ErbB2/ErbB3 heterodimer functions as an oncogenic unit: ErbB2 requires ErbB3 to drive breast tumor cell proliferation. Proc Natl Acad Sci USA 2003, 100:8933-8938.

5. Brachmann SM, Hofmann I, Schnell C, Fritsch C, Wee S, Lane H, Wang S, Garcia-Echeverria C, Maira SM: Specific apoptosis induction by the dual PI3K/mTor inhibitor NVP-BEZ235 in HER2 amplified and PIK3CA mutant breast cancer cells. Proc Natl Acad Sci USA 2009, 106:22299-22304.

6. O'Brien C, Wallin JJ, Sampath D, GuhaThakurta D, Savage H, Punnoose EA, Guan J, Berry L, Prior WW, Amler LC, Belvin M, Friedman LS, Lackner MR: Predictive biomarkers of sensitivity to the phosphatidylinositol 3 ' kinase inhibitor GDC-0941 in breast cancer preclinical models. Clin Cancer Res 2010, 16:3670-3683.

7. Junttila TT, Akita RW, Parsons K, Fields C, Lewis Phillips GD, Friedman LS, Sampath D, Sliwkowski MX: Ligand-independent HER2/HER3/PI3K complex is disrupted by trastuzumab and is effectively inhibited by the PI3K inhibitor GDC-0941. Cancer Cell 2009, 15:429-440.

8. Ritter CA, Perez-Torres M, Rinehart C, Guix M, Dugger T, Engelman JA, Arteaga CL: Human breast cancer cells selected for resistance to trastuzumab in vivo overexpress epidermal growth factor receptor and ErbB ligands and remain dependent on the ErbB receptor network. Clin Cancer Res 2007, 13:4909-4919.

9. Yakes FM, Chinratanalab W, Ritter CA, King W, Seelig S, Arteaga CL: Herceptin-induced inhibition of phosphatidylinositol-3 kinase and Akt Is required for antibody-mediated effects on p27, cyclin D1, and antitumor action. Cancer Res 2002, 62:4132-4141.

10. Saal LH, Holm K, Maurer M, Memeo L, Su T, Wang X, Yu JS, Malmström PO, Mansukhani M, Enoksson J, Hibshoosh H, Borg A, Parsons R: PIK3CA mutations correlate with hormone receptors, node metastasis, and ERBB2, and are mutually exclusive with PTEN loss in human breast carcinoma. Cancer Res 2005, 65:2554-2559.

11. Samuels Y, Wang Z, Bardelli A, Silliman N, Ptak J, Szabo S, Yan H, Gazdar A, Powell SM, Riggins GJ, Willson JK, Markowitz S, Kinzler KW, Vogelstein B, Velculescu VE: High frequency of mutations of the PIK3CA gene in human cancers. Science 2004, 304:554.

12. Zhao L, Vogt PK: Helical domain and kinase domain mutations in $\mathrm{p} 110 \mathrm{a}$ of phosphatidylinositol 3-kinase induce gain of function by different mechanisms. Proc Natl Acad Sci USA 2008, 105:2652-2657.

13. Koboldt DC, Fulton RS, McLellan MD, Schmidt H, Kalicki-Veizer J, McMichael JF, Fulton LL, Dooling DJ, Ding L, Mardis ER, Wilson RK, Ally A, Balasundaram M, Butterfield YS, Carlsen R, Carter C, Chu A, Chuah E, Chun HJ, Coope RJ, Dhalla N, Guin R, Hirst C, Hirst M, Holt RA, Lee D, Li HI, Mayo M, Moore RA, Mungall AJ, Cancer Genome Atlas Network, et al: Comprehensive molecular portraits of human breast tumours. Nature 2012, 490:61-70.

14. Stemke-Hale K, Gonzalez-Angulo AM, Lluch A, Neve RM, Kuo WL, Davies M, Carey M, Hu Z, Guan Y, Sahin A, Symmans WF, Pusztai L, Nolden LK, Horlings H, Berns K, Hung MC, van de Vijver MJ, Valero V, Gray JW, Bernards R, Mills GB, Hennessy BT: An integrative genomic and proteomic analysis of PIK3CA, PTEN, and AKT mutations in breast cancer. Cancer Res 2008, 68:6084-6091.

15. Berns K, Horlings HM, Hennessy BT, Madiredjo M, Hijmans EM, Beelen K, Linn SC, Gonzalez-Angulo AM, Stemke-Hale K, Hauptmann M, Beijersbergen RL, Mills GB, van de Vijver MJ, Bernards R: A functional genetic approach identifies the PI3K pathway as a major determinant of trastuzumab resistance in breast cancer. Cancer Cell 2007, 12:395-402.

16. Eichhorn PJA, Gili M, Scaltriti M, Serra V, Guzman M, Nijkamp W, Beijersbergen RL, Valero V, Seoane J, Bernards R, Baselga J: Phosphatidylinositol 3-kinase hyperactivation results in lapatinib resistance that is reversed by the $\mathrm{mTOR} /$ phosphatidylinositol 3-kinase inhibitor NVP-BEZ235. Cancer Res 2008, 68:9221-9230.

17. Serra V, Markman B, Scaltriti M, Eichhorn PJA, Valero V, Guzman M, Botero ML, Llonch E, Atzori F, Di Cosimo S, Maira M, Garcia-Echeverria C, Parra JL, Arribas J, Baselga J: NVP-BEZ235, a dual PI3K/mTOR inhibitor, prevents PI3K signaling and inhibits the growth of cancer cells with activating PI3K mutations. Cancer Res 2008, 68:8022-8030

18. Nagata Y, Lan KH, Zhou X, Tan M, Esteva FJ, Sahin AA, Klos KS, Li P, Monia BP, Nguyen NT, Hortobagyi GN, Hung MC, Yu D: PTEN activation 
contributes to tumor inhibition by trastuzumab, and loss of PTEN predicts trastuzumab resistance in patients. Cancer Cell 2004, 6:117-127.

19. Chandarlapaty S, Sakr RA, Giri D, Patil S, Heguy A, Morrow M, Modi S, Norton L, Rosen N, Hudis C, King TA: Frequent mutational activation of the PI3K-AKT pathway in trastuzumab-resistant breast cancer. Clin Cancer Res 2012, 18:6784-6791.

20. Baselga J, Bradbury I, Eidtmann H, Di Cosimo S, de Azambuja E, Aura C, Gómez H, Dinh P, Fauria K, Van Dooren V, Aktan G, Goldhirsch A, Chang TW, Horváth Z, Coccia-Portugal M, Domont J, Tseng LM, Kunz G, Sohn JH, Semiglazov V, Lerzo G, Palacova M, Probachai V, Pusztai L, Untch M, Gelber RD, Piccart-Gebhart M, NeoALTTO Study Team: Lapatinib with trastuzumab for HER2-positive early breast cancer (NeoALTTO): a randomised, open-label, multicentre, phase 3 trial. Lancet 2012, 379:633-640.

21. Blackwell KL, Burstein HJ, Storniolo AM, Rugo HS, Sledge G, Aktan G, Ellis C, Florance A, Vukelja S, Bischoff J, Baselga J, O'Shaughnessy J: Overall survival benefit with lapatinib in combination with trastuzumab for patients with human epidermal growth factor receptor 2-positive metastatic breast cancer: final results from the EGF104900 Study. J Clin Oncol 2012, 30:2585-2592.

22. Baselga J, Cortés J, Kim SB, Im SA, Hegg R, Im YH, Roman L, Pedrini JL, Pienkowski T, Knott A, Clark E, Benyunes MC, Ross G, Swain SM, CLEOPATRA Study Group: Pertuzumab plus trastuzumab plus docetaxel for metastatic breast cancer. N Engl J Med 2012, 366:109-119.

23. Amin DN, Sergina N, Ahuja D, McMahon M, Blair JA, Wang D, Hann B, Koch KM, Shokat KM, Moasser MM: Resiliency and vulnerability in the HER2HER3 tumorigenic driver. Sci Transl Med 2010, 2:16ra7.

24. Hanker AB, Pfefferle AD, Balko JM, Kuba MG, Young CD, Sánchez V, Sutton CR, Cheng H, Perou CM, Zhao JJ, Cook RS, Arteaga CL: Mutant PIK3CA accelerates HER2-driven transgenic mammary tumors and induces resistance to combinations of anti-HER2 therapies. Proc Natl Acad Sci USA 2013, 110:14372-14377.

25. Rexer BN, Ham AJL, Rinehart C, Hill S, de Matos Granja-Ingram N, GonzálezAngulo AM, Mills GB, Dave B, Chang JC, Liebler DC, Arteaga CL: Phosphoproteomic mass spectrometry profiling links Src family kinases to escape from HER2 tyrosine kinase inhibition. Oncogene 2011, 30:4163-4174.

26. Isakoff SJ, Engelman JA, Irie HY, Luo J, Brachmann SM, Pearline RV, Cantley LC, Brugge JS: Breast cancer-associated PIK3CA mutations are oncogenic in mammary epithelial cells. Cancer Res 2005, 65:10992-11000.

27. Dias-Santagata D, Akhavanfard S, David SS, Vernovsky K, Kuhlmann G, Boisvert SL, Stubbs H, McDermott U, Settleman J, Kwak EL, et al: Rapid targeted mutational analysis of human tumours: a clinical platform to guide personalized cancer medicine. EMBO Mol Med 2010, 2:146-158.

28. Su Z, Dias-Santagata D, Duke M, Hutchinson K, Lin YL, Borger DR, Chung $\mathrm{CH}$, Massion PP, Vnencak-Jones $\mathrm{CL}$, lafrate AJ, Pao W: A platform for rapid detection of multiple oncogenic mutations with relevance to targeted therapy in non-small-cell lung cancer. J Mol Diagn 2011, 13:74-84.

29. Lovly CM, Dahlman KB, Fohn LE, Su Z, Dias-Santagata D, Hicks DJ, Hucks D, Berry E, Terry C, Duke M, Su Y, Sobolik-Delmaire T, Richmond A, Kelley MC, Vnencak-Jones $\mathrm{CL}$, lafrate AJ, Sosman J, Pao W: Routine multiplex mutational profiling of melanomas enables enrollment in genotype-driven therapeutic trials. PLoS One 2012, 7:e35309.

30. Engelman JA, Jänne PA, Mermel C, Pearlberg J, Mukohara T, Fleet C, Cichowski K, Johnson BE, Cantley LC: ErbB-3 mediates phosphoinositide 3-kinase activity in gefitinib-sensitive non-small cell lung cancer cell lines. Proc Natl Acad Sci USA 2005, 102:3788-3793.

31. Huang $\mathrm{CH}$, Mandelker D, Schmidt-Kittler O, Samuels $Y$, Velculescu VE, Kinzler KW, Vogelstein B, Gabelli SB, Amzel LM: The structure of a human p110a/ p85a complex elucidates the effects of oncogenic PI3Ka mutations. Science 2007, 318:1744-1748.

32. Garrett JT, Olivares MG, Rinehart C, Granja-Ingram ND, Sánchez V, Chakrabarty A, Dave B, Cook RS, Pao W, McKinely E, Manning HC, Chang J, Arteaga CL: Transcriptional and posttranslational up-regulation of HER3 (ErbB3) compensates for inhibition of the HER2 tyrosine kinase. Proc Nat/ Acad Sci USA 2011, 108:5021-5026.

33. Chakrabarty A, Rexer BN, Wang SE, Cook RS, Engelman JA, Arteaga CL: H1047R phosphatidylinositol 3-kinase mutant enhances HER2-mediated transformation by heregulin production and activation of HER3. Oncogene 2010, 29:5193-5203.

34. Miller TW, Rexer BN, Garrett JT, Arteaga CL: Mutations in the phosphatidylinositol 3-kinase pathway: role in tumor progression and therapeutic implications in breast cancer. Breast Cancer Res 2011, 13:224.
35. Yao E, Zhou W, Lee-Hoeflich ST, Truong T, Haverty PM, Eastham-Anderson J, Lewin-Koh N, Gunter B, Belvin M, Murray LJ, Friedman LS, Sliwkowski MX Hoeflich KP: Suppression of HER2/HER3-mediated growth of breast cancer cells with combinations of GDC-0941 PI3K inhibitor, trastuzumab, and pertuzumab. Clin Cancer Res 2009, 15:4147-4156.

36. García-García C, Ibrahim YH, Serra V, Calvo MT, Guzmán M, Grueso J, Aura C Pérez J, Jessen K, Liu Y, Rommel C, Tabernero J, Baselga J, Scaltriti M: Dual mTORC1/2 and HER2 blockade results in antitumor activity in preclinical models of breast cancer resistant to anti-HER2 therapy. Clin Cancer Res 2012, 18:2603-2612.

37. Chakrabarty A, Sánchez V, Kuba MG, Rinehart C, Arteaga CL: Feedback upregulation of HER3 (ErbB3) expression and activity attenuates antitumor effect of PI3K inhibitors. Proc Nat Acad Sci USA 2012, 109:2718-2723.

38. Serra V, Scaltriti M, Prudkin L, Eichhorn PJ, Ibrahim YH, Chandarlapaty S, Markman B, Rodriguez O, Guzman M, Rodriquez S, Gili M, Russillo M, Parra JL, Singh S, Arribas J, Rosen N, Baselga J: PI3K inhibition results in enhanced HER signaling and acquired ERK dependency in HER2-overexpressing breast cancer. Oncogene 2011, 30:2547-2557.

39. Baselga J, Cortés J, Im SA, Kiermaier A, Ross G, Swain SM: Biomarker analyses in CLEOPATRA: a phase III, placebo-controlled study of pertuzumab in HER2-positive, first-line metastatic breast cancer (MBC). Cancer Res 2012, 72:Abstract nr 55-1.

\section{doi:10.1186/bcr3601}

Cite this article as: Rexer et al.: Direct inhibition of PI3K in combination with dual HER2 inhibitors is required for optimal antitumor activity in HER2+ breast cancer cells. Breast Cancer Research 2014 16:R9.

\section{Submit your next manuscript to BioMed Central and take full advantage of:}

- Convenient online submission

- Thorough peer review

- No space constraints or color figure charges

- Immediate publication on acceptance

- Inclusion in PubMed, CAS, Scopus and Google Scholar

- Research which is freely available for redistribution

Submit your manuscript at www.biomedcentral.com/submit
C) Biomed Central 